\title{
Financial accounting and reporting: Sustaining relevance in the present time paradigm
}

\author{
DG Gouws \\ School of Financial Sciences \\ University of Pretoria
}

A Rehwinkel

School of Accounting University of South Africa

\begin{abstract}
Accountants are looking for innovative solutions to challenges and problems that seem to become increasingly numerous and complicated. Researchers debate whether the emergence of these challenges is due to a general dissatisfaction with the existing accounting paradigm. This article therefore presents a transdisciplinary approach aimed at creating a new accounting paradigm.

The discipline of accounting is challenged by blending the limitations within the present paradigm with the discoveries in physics and quantum mechanics. This study shifts the attention to those aspects of reality that characterise today's accelerated social change, disorder, instability, diversity, disequilibrium and non-linear relationships - all with a heightened sensitivity to the flow of time. By interpreting financial accounting and reporting from this perspective, new perspectives are offered from a holistic paradigm of transcendence in relation to the arrow of time and information capacity.
\end{abstract}

\section{Key words}

Accounting constraints

Intelligence

Artistic elements

Relationships

Dissipative systems

Transcendence

Financial reporting

Time paradigm

\section{Introduction}

The current financial accounting and reporting system is strongly attached to roots of tradition and convention; of sound Newtonian thinking. Its structure, accordingly, is classical, deterministic and fragmented; totally unrelated to the dissipative qualities of its present-day environment. The system prefers to adopt systemic

Meditari Accountancy Research Vol. 12 No. 12004 : 77-99 
qualities that characterise certainty and predictability at the cost of increasing alienation and perplexity.

The 20th century induced upon mankind mysterious and unforeseeable change in virtually all aspects of scientific development, implicating inescapable and increasing uncertainty, complexity, risk and challenge. Survival became dependent on the reaction to these peculiar phenomena, which invoke innovation by gathering new connections "from insights gained by journeys into other disciplines or places; from active, collegial networks and fluid open boundaries" (Wheatley 1999:104).

This article is based on the hypothesis that the nature and the position of the current financial accounting and reporting system, in relation to the demands set by phenomena such as mentioned in the above, are too rigid, enclosed and detached to secure its survival in a complex time paradigm such as the present.

Acknowledging the vast research possibilities of such an hypothesis, the main goals of this article were restricted to 1) investigating a number of the major factors that cause such constraints, 2) evaluating the current position of the accounting and reporting system from a transdisciplinary paradigm and 3) recommending solutions to enhance the viability of the system.

The article commences with a discussion of the main derivatives of the nature of the prevailing financial accounting and reporting system as seen from an historical perspective, as well as a study of the incongruent artistic and scientific nature thereof. Against this background, limitations of the system are discussed to assist in the illustration of the position thereof in relation to the modern concepts of the arrow of time and cumulative information capacity. In conclusion, recommendations are made to address the system's constraints.

\section{Problem statement and research methodology}

\subsection{Background}

It is indeed striking that the so-called "intellectual elite" of the 21st century, the people who are supposed to be experts in their various fields, are frequently failing in their attempts to embed a trust in and enhance the stature of their professions (Baxter 1988; Lee 1989; Wells 1987). In spite of vast technological advancements that could be liberally applied in these attempts, they seem to be able to render neither a service nor a product with sound quality or to assist in the evolvement of their professions by adjusting to changing times.

This predicament also applies to the accounting profession, where a study of the development and the current discrepancies of the financial accounting and reporting system indicates that very little useful growth, if any, has taken place since the 15th century (Lee 1990). Although seemingly infinite changes have been made to enhance the profession, developments have been focused mostly on measures to safeguard its stature and independence, such as international standardisation. These attempts mainly encouraged the rigid and directive nature of the system and did not 
make a substantial contribution towards alleviating the causes of the problems it had been exposed to. Goldberg (2001:92), for example, concludes that " $[t]$ he availability of these standards, however well-intentioned they may be, does nothing to remove the dilemma or to solve the problem; they are merely part of the plastering process".

With such a predominant inward orientation, the accounting system is captured within the monotonous cycle of re-wrapping the same product, thereby creating an illusion of progress, truth and vitality.

For centuries the accounting discipline has functioned in the "secure" realm of legislation, regulations, rules and the like. It has positioned itself in a highly structured comfort zone, where principles such as responsibility and accountability can readily be diverted from within the parameters of ambiguous disclosure. Turning itself away from the pressure of achieving the main and rather subjective objective of usefulness, it also locks out the possibilities of exploration, creation and adaptation. Elliott (1991:2) confirms in this regard that ". . . our industrial-era accounting paradigm is actually holding us back".

The accounting discipline lacks the broader perception that it actually does possess the ability to fulfil its purpose in many ways. It seems hypnotised by a bureaucratic hierarchy and is constantly reminded of its incapabilities, which steal from the discipline its freedom to question and adjust. Duties are performed religiously according to standards, regardless of the qualitative characteristics, such as clarity, thereof. The collective intelligence potential of the profession is significantly controlled in this way.

However, the disciplinary harness of standardisation does not represent a solution to disclosure problems, since sensitive information can still be skilfully and legitimately desensitised in financial reports. As the Enron debacle emphasised: “The press calls them 'off-balance-sheet partnerships' - those hundreds of Enron entities that were used to hide their debt and book illusory profits. ... [t]hey offer plenty of temptation for companies looking for legal ways to cook the books" (Kahn 2002:1).

The substantial amount of accounting scandals and inefficiencies evokes a further increase in the implementation of legislative control measures on an already highly restricted profession in order to improve its current questionable professional stature. As a result, the accounting profession as a system is incrementally cocooning itself from its insecurities, alienating itself from reality. It is disconnecting itself from its web of relationships - its "raison d'être"- and seems destined for senseless exercises in delivering fiction instead of fact, until it will completely lose its purpose and disintegrate.

\subsection{Problem statement}

The research problem can be stated as the inability of the current global financial accounting and reporting system to embed and enhance the relevance of the 
profession and its products in a highly informational and technologically oriented environment in the midst of ever-increasing changes in all of its facets and relationships.

\subsection{Research methodology}

At present, accounting research is extending its boundaries well beyond the boundaries presented by pure normative and empirical research methods of the past decades (Wolk, Tearney and Dodd 2001).

Nicolescu, for example, made it clear that any topic in accounting will ultimately be enriched by a fusion of the perspectives of several disciplines. He remarked that "... our understanding of certain phenomena in terms of its own discipline (accounting) is deepened by a fertile multidisciplinary approach" (1999:1). Sterling also concluded that ". . . all of the accounting research methods from all of these other disciplines are appropriate for accounting. To put it another way, the goal of research is to obtain results which will contribute to our knowledge ..." This rather sweeping conclusion is likely to be disappointing to those who had expected me to label some research methods as 'unscientific' and to endorse others" (1972:3).

A discipline such as accounting should thus be studied not only from an accountant's frame of mind, but also with a view towards blending accounting with physics, quantum mechanics, economics, etc.

A multidisciplinary approach brings a "plus" to disciplines. Its goal is the understanding of the present world. Transdisciplinary research is not antagonistic, but complementary. It overflows the discipline of accounting, but its goal still remains within the framework of accounting research.

By interpreting accounting and accounting phenomena from a broader perspective, new forms and realities under uncertain circumstance are generated to be considered for testing. According to Kapur and Kesavan "[u]ncertainty plays a very significant role in our differing perceptions about the external world. Any discipline that can assist us in understanding it, measuring it, regulating it, maximizing or minimizing it, and ultimately controlling it to the extent possible, should certainly be considered an important contribution to our scientific understanding of complex phenomena" (1992:2).

In an attempt to align with transdisciplinary research methods, this article presents a philosophical transdisciplinary study with a systematic view of problem solving. According to the Mitroff model, such a systematic approach may include "conceptualisation, modelling, model solving and implementation" (Koornhof 2001:256). Embarking from the initial stage of this extensive research topic, the focus was placed on the aspects of conceptualisation and modelling. 


\section{Main derivatives of the nature of the prevalent system}

An understanding of the current nature of the financial accounting and reporting system calls for the attainment of a broader perspective on the foundation, structure and operations thereof. Such an endeavour requires, among others, a study of the system's development, as well as of the effect that the incorporation of artistic and scientific elements had on its nature. A discussion of these two areas will be regarded as sufficient to gain a primary insight into the rationale behind the development of the system's characteristics.

\subsection{A synopsis of financial accountancy history}

Studies in financial accountancy history (Edwards 1989; Garbutt 1981; Mattesich 2000) reveal that the financial accounting and reporting system was developed over an extensive time span. It was characterised by slow, random, re-active and unempirical growth. From the outset, the accounting profession was highly unregulated, seeking to satisfy first of all its own needs at the expense of disclosing information with sincerity. The profession was founded on tradition and convention, whereby its disaccord with empirical science was secured. Rigid regulations were implemented which resulted in the underutilisation of the system's creative and innovative potential. This "recipe book" approach frequently vindicated ineffective practices. Valuable time was wasted on debating insignificant issues such as the relative importance of financial statements instead of addressing factors such as the nature and goal of accountancy. The developmental focus was inwards, on securing the status of the profession and safeguarding itself against governmental intervention by implementing standards, rules, etc. The profession was not directed outwards towards its environment, such as in considering the needs of the stakeholders.

Nonetheless, governmental and corporate interventions inhibited the independence and scientific nature of the profession (Dwyer 2000; Evans 2003). There was no clear sense of identity or direction, only a climate of significant indecisiveness. The focal point was too narrow and external regulations too overwhelming, resulting in increased and recurrent accountancy problems.

\subsection{The effect of incongruent artistic and scientific elements on the system}

An analysis of the foundation and the practical nature of the system indicates that it possesses both artistic and predominantly classical scientific elements that often have opposing attributes which are detrimental to the quality of the service the system renders (Sterling 1997; Wolpert 1993).

Classical science focuses on explanation and on ". . . laying bare the fundamental mechanisms of nature. That's what biologists, geologists and astronomers do in 
their fields" (Waldrop 1992:39). Art is not necessarily concerned about presenting an accurate portrayal of an object. In fact, different representations of the same object are not only acceptable but also desirable. Unlike the classical sciences, art does not endeavour to avoid interpretational differences.

Accounting is often defined as an art. It is an artificial science consisting of knowledge about artificial objects and phenomena. Artificial refers to the nonnatural. Accounting is a human activity that is concerned with human activities (Gouws 1997). The accounting product is a human artefact and not a natural phenomenon, which has more bearing on the classical sciences. Its product is art (hence the definition), a perception of reality.

Since accounting is an artefact - a product of human intervention designed by humans for human purposes (Parker, Ferris and Otley 1989; Goldberg 2001), its process and product is art - our perception of reality.

As mentioned in the Introduction, scientific discoveries of the 20th century compelled important changes to the perception of the predominantly deterministic sciences of the 19th century. The latter were unconcerned about the ramifications that could be instilled by factors such as the arrow of time and contingency. The more modern science seemed to "learn" about nature, the more unpredictable and chaotic nature became. Modern science revealed itself to be complex and limitless, functioning from an uncertain, open environment.

Whereas art and classical science are disparate by nature, both art and modern science acknowledge the attribute of contingency. By acknowledging the concept of contingency, it is virtually impossible to make verified empirical propositions about systems, since, given different circumstances, both systems and propositions are prone to adaptation. This contingent element is also transferred to the accounting system, confirming the notion that it could never fall in the realm of pure classical science, being founded on pure classical accountancy theory.

Depending on the selection of artistic and scientific attributes, they can either synergise or neutralise systemic energy. For example, to attain synergy, the innovative and visionary attributes of art should be embedded in an accounting system, as it has the potential to enhance scientific matter. Artistic attributes that oppose the ideals of science, such as diverse interpretation and randomness, will have an adverse effect on the system.

Table 1 illustrates the manner in which these attributes are integrated into the financial accounting and reporting system. From the table it is clear that the system is striving to create a foundation based on the conventions of the classical sciences (Evans 2003), such as objectivity and consistency. It favours growth through empirical research. It aspires, via its statements for example, to be deterministic and objective. It has made numerous attempts to produce a unified accounting theory. It aspires to explain, understand and predict. However, due to the modern-day phenomena exposed by the discoveries in physics and quantum mechanics (such as complexity, uncertainty and change), the operational process of the system does not complement its classical scientific-oriented foundation. In practice, the system is 
more artificially inclined and relies more on the virtues of the modern sciences. For example, it presents a mere abstract interpretation of reality; its development is random and reactive, and there is a multiple interpretation of the products that it delivers. The foundation of the system is thus disparate from what it practises. This results in constraints such as ambiguity, delusion and detachment.

Table 1 The impact of artistic attributes on the current financial accounting and reporting system, as opposed to the theory of the classical sciences according to which the foundations of the system have been developed

\begin{tabular}{|c|c|c|}
\hline $\begin{array}{l}\text { MACRO AND } \\
\text { DETERMINISTIC } \\
\text { ORIENTATION }\end{array}$ & $\begin{array}{l}\text { MICRO AND IN- } \\
\text { DETERMINISTIC } \\
\text { ORIENTATION }\end{array}$ & \\
\hline $\begin{array}{c}\text { CURRENT } \\
\text { THEORETICAL } \\
\text { FOUNDATION OF THE } \\
\text { FINANCIAL } \\
\text { ACCOUNTING AND } \\
\text { REPORTING SYSTEM } \\
\text { ACCORDING TO THE } \\
\text { SOCIAL AND } \\
\text { CLASSICAL SCIENCES }\end{array}$ & $\begin{array}{c}\text { CURRENT PRACTICAL } \\
\text { NATURE OF THE } \\
\text { FINANCIAL } \\
\text { ACCOUNTING AND } \\
\text { REPORTING SYSTEM } \\
\text { EMBEDDED IN ARTISTIC } \\
\text { ATTRIBUTES }\end{array}$ & $\begin{array}{l}\text { RESULTANT CONDUCT } \\
\text { OF THE SYSTEM }\end{array}$ \\
\hline \multicolumn{3}{|c|}{1 Goal of the financial accounting and reporting system } \\
\hline $\begin{array}{l}\text { "Truth and reality", objec- } \\
\text { tivity, consistency }\end{array}$ & $\begin{array}{l}\text { Abstract interpretation of } \\
\text { reality, impression, opinion }\end{array}$ & $\begin{array}{l}\text { Ambiguity, delusion, sub- } \\
\text { jectivity, flexibility }\end{array}$ \\
\hline \multicolumn{3}{|c|}{2 Development of a financial accounting and reporting system } \\
\hline Empirical research & Random, re-active & Non-empirical research \\
\hline \multicolumn{3}{|c|}{3 Operational structure of financial accounting and reporting system } \\
\hline $\begin{array}{l}\text { Empirical, deterministic, } \\
\text { objective identification and } \\
\text { measurement, enclosure, } \\
\text { matter oriented, normative, } \\
\text { value free }\end{array}$ & $\begin{array}{l}\text { Impression, mind oriented, } \\
\text { moral overtone, ambigu- } \\
\text { ous measurement }\end{array}$ & $\begin{array}{l}\text { Tradition, convention, } \\
\text { manipulation, exploitation, } \\
\text { ambiguity, communication } \\
\text { of matter from imaginative } \\
\text { mind-set, et cetera }\end{array}$ \\
\hline \multicolumn{3}{|c|}{4 Focal point of a financial accounting and reporting system } \\
\hline $\begin{array}{l}\text { Unifying theory, universal } \\
\text { needs, generalise }\end{array}$ & $\begin{array}{l}\text { Broad as well as narrow } \\
\text { scope }\end{array}$ & $\begin{array}{l}\text { Universal and specific } \\
\text { needs }\end{array}$ \\
\hline \multicolumn{3}{|l|}{5 Utilisation of the product } \\
\hline $\begin{array}{l}\text { Strict defined meaning, } \\
\text { explanation, understand, } \\
\text { predict }\end{array}$ & $\begin{array}{l}\text { Multiple interpretation, } \\
\text { interrelate, feeling }\end{array}$ & Subjective, incomplete \\
\hline
\end{tabular}


The classical sciences, in which the formal and pre-determined theoretical foundation of the current financial accounting and reporting system is embedded, are macro-oriented and deterministic. On the other hand, the operational structure of the system is naturally moulded by in-deterministic artistic attributes according to its changing landscape as far as the rigid theoretical construction will allow it to adjust. Unaligned artistic and scientific attributes cause disparate thinking in prevailing accounting thought.

\section{Limitations of an ambivalent financial accounting and reporting system}

The limitations of the current system, as far as meaningfulness is concerned, have been elaborated upon exhaustively in financial literature (Evans 2003; Francis and Schipper 1999; Lev and Zarowin 1999; Sterling 1997). The constant failure to present fair and full reports and to display proper ethical conduct is a typical problem that has plagued the profession from its inception until today (Green 1930; Evans 2003).

The contradictory nature of the system has caused it to become detached from its users, fragmented instead of interrelated, oversimplified whilst too complex, ambiguous, unstable and unempirical (Lee 1990). It fails to recognise, for example, that a data overload can produce informational shortages. There is a tendency to generalise and a disregard to adjust to the system's changing environment. Accounting literature focuses increasingly on such inflexibility, which causes intangible factors not to be reported on, a lack in the utilisation of modern communication technologies, an inability to report on information-oriented corporations, etc. (Lymer 1998). Portrayals of the past are distorted and characterised by significant diversity. "Financial accounting and business reporting had in fact not kept pace with the changes in the business world" (Evans 2003:343).

Since it is not the aim of this article to present an exhaustive list of anomalies, but to determine the causes thereof, four limitations currently experienced are mentioned for illustrative purposes:

\section{Uncertain application of the concept of usefulness}

The accounting profession appears to be uncertain as far as the application of the concept of usefulness is concerned. The perception exists that the profession does not have clarity on the objective of usefulness itself. In this regard Flegm claims that the FASB now lacks "any consensus as to the purpose of accounting and financial statements" (2000:6). As a result, the system becomes disoriented.

Furthermore, whilst striving towards the goal of usefulness, adjustments of financial reports according to the changed operations and structure of organisations as well as according to the needs of the "new generation" of users seem obvious. Yet, "[t]his change has not occurred" (Anonymous 2000:2). The profession needs to realise that " $[\mathrm{k}]$ nowledge grows inside relationships, from ongoing circles of 
exchange where information is not just accumulated by individuals, but is willingly shared" (Wheatley 1999:104).

\section{Limitations in current accounting theory}

Studies of accounting theory (Evans 2003; Goldberg 2001; Sterling 1997; Yu 1976) have revealed limitations such as impracticality, creating opportunities for arbitrary allocation, a normative emphasis, a lack of a cost-benefit analysis and an inability to consider the implications of data overflow. An important difference between current accounting theory and theories related to other disciplines, which must be taken note of, is the strong emphasis that the other disciplines place on 1) formal research methodology, 2) the truth criteria and 3) the attempts to explain what is, instead of what should be.

\section{Ambiguous accounting terminology}

For illustrative purposes, the practical difficulties with regard to the enactment of the going concern concept will be discussed. One of the greatest changes in accounting procedure was when the venture concept was replaced with the going concern concept. The timing of measurement was hereby shifted from the awaiting of a future event to measurement at a specific point in time. Currently, the going concern concept is universally accepted, and yet to date it is not well defined, resulting in irresolvable conceptual confusion. The going concern concept imposes the danger that the concept of time, and more specifically of the past and the future, can be incorrectly interrelated. Thereby the disclosure of "reality" over a given period or at a given point in time may be distorted. Since financial statements are prepared according to historical cost measurement procedures and simultaneously adhere to the futuristic going concern concept, a rather odd state of affairs is devised, namely that financial statement figures contain "provisional, estimated or contingent" futuristic allocations that are based on historical cost measurements.

This problem has not been sufficiently addressed, although the profession strives towards the ultimate goal of science, namely to "formulate general laws which have the power to explain and to predict with a high degree of certainty" (Yu 1976:10). However, ". . . the search for accounting principles which began consciously and deliberately in the English speaking world in the 1930s has not yet produced anybody of reliable knowledge which can serve as a basis for development comparable in any way with that of any of the natural sciences" (Goldberg 2001:56).

Sterling elaborated on such time-related irregularities and mentioned that "[a]n asset is an asset because it will benefit the future and is valued on the present balance sheet on the basis of a past price. The firm will have to continue in the future in the manner expected at the present in order for the present allocations or past expenditures to be correct while the past allocations made on the basis of the past expectations of future events now need to be corrected to reflect present expectations of future events" (1997:498). 
Observed from this context the problem lies in the definition of "true value", given as the liquidation value at the time of liquidation. Future magnitudes cannot be measured, thus making the definition of true value unmeasurable. According to Sterling (1997), measurement is the discovery of an extant condition that requires a present act. He asserted that future magnitudes can be predicted and verified as they occur, but that measurements need to be made in the present.

\section{Pressure to realise estimations}

When an estimate is made, there exists pressure to assure its outcome, thereby restricting the accountant to lesser possibilities. In addition, it results in major revision difficulties.

\section{The position of the current system viewed from a transdisciplinary paradigm}

The present position and nature of the system are illustrated in Diagram 1, which the authors constructed from the information as presented in the aforementioned paragraphs as well as from further transdisciplinary readings, such as in the social sciences, physics and philosophy (e.g. Capra 1997; Horwich 1992; Prigogine 1997; Zohar and Marshall 2001). The purpose of the diagram is to offer a transdisciplinary and holistic perspective on the aspects of the system in relation to the arrow of time and information capacity. In this respect it is assumed that the arrow of time refers to the fact that time is moving forward at an accelerating pace, causing increased uncertainty, risk and complexity as the environment of systems become more globalised. As time moves forward, the importance of the Newtonian concept of cause and effect, of deterministic behaviour and the possibility of prediction according to past trends decreases as the process of interrelatedness escalates. 


\section{Diagram 1 A transdisciplinary paradigm of transcendence in relation to} the arrow of time and information capacity

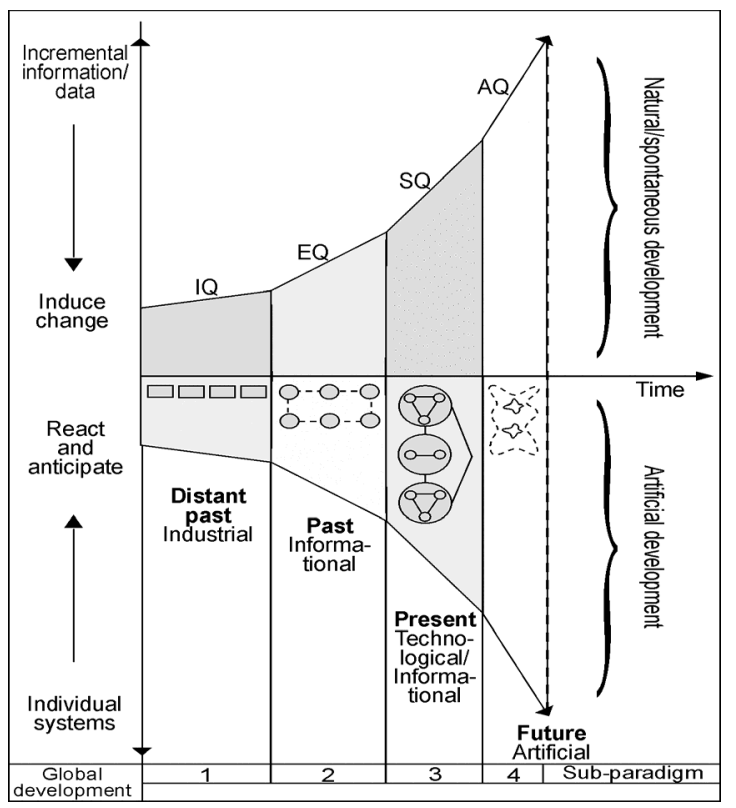

Source: Author's own interpretation.

\subsection{Features of the diagram}

According to the diagram, the aspects 1) time spans and 2) information are portrayed on the $\mathrm{x}$ - and $\mathrm{y}$-axis respectively. They move in opposite directions - as information increases, the time span will decrease since more information can be accommodated in less time. This is the phenomenon that causes unpredictable change and "there has been more change in the last fifty years than since the Stone Age ... Uncertainty and unpredictability impeded, compass needles no longer had a North, maps became useless" (Zohar and Marshall 2001:200).

In the diagram, time is divided into four informational eras. Each era can be considered to be a subparadigm. Each subparadigm consists of three components, namely a phase-time-pace, an intellectual capacity and a system.

\subsubsection{Subparadigm 1}

Phase-time-pace (industrial-distant past-lengthened/slow) - The phase-time-pace of Subparadigm 1 refers to the "Industrial Age", to mechanical constructions according to the broader concepts of the universe that require lesser attributes and therefore lesser information when reality is modelled. At this stage the level of information is restricted and simple. The focus is predominantly on the study of 
"matter" according to the classical sciences. The arrow of time plays an insignificant role, as elementary scientific assumptions are deterministic - the principle of cause and effect applies. Lesser information implies slower change and consequently a longer time span. From the perspective of Subparadigm 4, this paradigm refers to the distant past.

Intellectual capacity - The level of intelligence that was necessary to cope within an "Industrial Age" was mainly cognitive (IQ). It was cognisance that created more information in this stage, until the cumulative growth of the information, which had been caused by the individual partaking systems, increased to where the phase-time-pace naturally transcended into the next subparadigm.

System - A longer time span accommodates systems that are predictable, closed and unrelated. The principle of cause and effect abides. Choices are deterministic and the arrow of time almost non-existent. Systems functioning in such a subparadigm are following the "building block" approach where aspects such as order, unrelatedness and rigidity were emphasised.

\subsubsection{Subparadigm 2}

Phase-time-pace (informational-past-increase) - For the purpose of this article, the era is referred to as the "Informational Age". This subparadigm experiences an increase in information and pace with a resultant decreased effect on the time span. At this stage, mechanical constructions are including more specified information, thereby applying both macro and micro viewpoints. It is at such a stage that the classical sciences transcend to incorporate the modern sciences, thereby baffling the classical scientists in their attempts to understand the universe (Prigogine 1997). They do not realise that it was the increase in information that naturally revealed their discoveries of uncertainty and in-determinism. In relation to Subparadigm 1, there was a paradigm shift from the broad to the specific. Detail requires more information, which implies the increase of the attributes with which to model reality. At this stage the level of information is growing exponentially; it is less constrained and more complex. The focus is shifted from pure "matter", to include "mind" factors. Such a shift, for example, caused exceptional growth in the social sciences, where the perception of people started to change as they were no longer regarded from a mechanistic point of view. From a Subparadigm 4 perspective, this paradigm refers to the past.

Intellectual capacity - Cognitive intelligence could not cope with the additional demands of the "Informational Age". This era required an enhanced form of intelligence, as both "mind" and "matter" had to be addressed. Cognitive intelligence (IQ) was extended to "Emotional Intelligence" (EQ). Daniel Goleman proved through the research results from neuroscientists and psychologists that this form of intelligence exists, and that it is just as important as IQ (Zohar and Marshall 2001). According to Glover he focused on five domains - "knowing one's emotions, managing these emotions, motivating oneself, recognising emotions in others and handling relationships. Other aspects of EI include persistence in the 
face of frustrations, keeping distress from swamping the ability to think, controlling impulses and, crucially, empathy" (2001:2).

System - The shortened time span and increased information necessitated a more fluid system that is more open, related and diverse. The principle of cause and effect is no longer relevant and the arrow of time becomes more definite. Due to increased information levels, which spontaneously induce change, systems move away from equilibrium as more chaos is observed. Activity increases in correlation to informational increases. As a result, a shift towards globalisation is observed informational barriers are broken down and more systems emerge. Organisations evolve into more flexible and adjustable entities.

\subsubsection{Subparadigm 3}

Phase-time-pace (hi-tech/informational-present-increase) - This era is referred to as the "Hi-technological/Informational Age" and is accompanied by exponential growth in information and pace with a resultant induction to change and a decrease in the time span. Information is becoming increasingly more specified, and more revelation on the micro level is gained. The importance of "mind" matters increases. The universe is perceived as becoming less deterministic as the time span decreases and the information levels increase. The concept of the arrow of time becomes more noticeable, hence irreversibility is more prominent. It is perceived that time is moving faster, as more information and changes are generated in a shorter time span. Such a scenario causes uncertainty and increases risk. Independent mechanistic viewpoints according to Newtonian thought are becoming increasingly redundant, and the need to apply holistic intelligence systems emerges. From the perspective of Subparadigm 4, this paradigm refers to the present.

Intellectual capacity - "Emotional Intelligence" is no longer sufficient to cope with the additional attributes of the "Hi-technological/Informational Age". This era requires an even more enhanced form of intelligence, as the "mind" and "matter" issues that need to be addressed become more demanding. EQ expands to SQ (spiritual intelligence). SQ represents the intelligence with which individuals "address and solve problems of meaning and value, the intelligence with which we can place our actions and our lives in a wider, richer, meaning-giving context, the intelligence with which we can assess that one course of action or one life-path is more meaningful than another. SQ is the necessary foundation for the effective functioning of both IQ and EQ. It is the ultimate intelligence (Zohar and Marshall 2001:4). Sufficient scientific evidence for the presence of SQ exists. To mention but a few - the research projects carried out by 1) the neuropsychologist Michael Persionger and W. Singer during the 1990s, 2) a neurologist, V.S. Ramachandran during 1997, and 3) the Harvard neurologist and biological anthropologist, Terrance Deacon, also during 1997 (Zohar and Marshall 2001). Stent mentions that the continuum between art and science readily complements the concept of different intelligences (2001). Artificial systems should thus endeavour to expand into systems with multiple intelligences. 
System - The system that correlates best with this era is the holistic intelligence system, which is dissipative and contingent by nature. The focus now should be on the quality of relationships, and not on the structure or unrelated parts of a system. Everything is perceived as temporary, as more changes take place in an even shorter time span. Shorter time spans influence the speed at which change takes place. The more sophisticated the subparadigm within which a system is functioning, the more quickly it needs to adjust.

\subsubsection{Subparadigm 4}

Phase-time-pace (artificial informational-future-increase) - This coming era is referred to as the "Artificial Informational Age". It may be accompanied by exponential growth in information with a resultant induction to change to such an extent that high technology simply cannot accommodate the challenges thereof. Mechanistic viewpoints according to Newtonian thought will regain importance as it relates strongly to artificial intelligence. Artificial spiritual intelligence systems could emerge.

Intellectual capacity - Spiritual intelligence will have to be enhanced as people become increasingly less able to deal with the exponential growth in information and change in an ever shortening time span. Additional artificial intelligence needs to be created and implemented. The possibility of downloading intelligence is therefore not as inconceivable as was originally perceived. The concept of "Robotic/Artificial Intelligence" (AQ) could emerge.

System - The system that would best suit this era is the artificial spiritual intelligence system, which pertains to the attributes of spiritual intelligence systems and enhances additional cognitive intelligence.

\subsection{The operational process of the paradigm}

The three components in each subparadigm function as a whole. They are interrelated and a change in one component will have an impact on the other. As a global system, the cumulative effect of their interactions will cause them to spontaneously transcend into the next informational subparadigm. These components cannot function in isolation and a component related to a specific era will not function effectively in another. It is in such situations that directionless and symptomatic problems start to emerge; where systems become disparate and dysfunctional. The paradigm functions in a reiterative manner - a specific level of cognisance becomes aware of its informational base according to which it can create systems, whereby further information is produced and the level of intelligence is enhanced, which affects the informational base and the creation of the systems. This process of growth will reiterate until it naturally transcends into a new informational realm.

Due to the relative lack of information, the speed of growth in Subparadigm 1 is slow initially. As information is created by the partaking individual systems, the 
cumulative, global effect on the growth of information causes transcendence into a new informational era, which induces an increase in the amount of the partaking systems.

An important point of which to take note is that neither of the individual systems has complete dominance over the other. However, the global growth in informational and intellectual capacity induces the forces of change on the development of individual systems, which should anticipate and react accordingly. Global effects are holistic and occur naturally. Individual systems are created in an artificial manner; they do not react solely to natural or cumulative impact.

No individual system can dictate global growth within its subparadigm because each system is created independently within the parameters of its own utilised informational and intellectual capacity. Systems should thus be primarily designed to cope with the cumulative impact of informational and intellectual growth.

The significance of the applicable informational and intellectual levels is frequently neglected in the process of a system's design, causing such a system to become dysfunctional. Dysfunctional systems are often structured according to unrelated theories of past informational subparadigms. As a result, they lack the ability to relate to the latest global systems and become unstable. The structure of a system should correlate with the informational and intellectual capacities of the present informational age (Subparadigm 3). The further a system's structure regresses into the past, the more trying the process of adjustment will become. An individual system has no alternative but to direct itself towards the future, the direction of the arrow of time. In failing to do so, it will eventually become too disparate to co-exist.

\subsection{An evaluation of the current financial accounting and reporting system from the perspective of a holistic paradigm of transcendence}

According to the components of the paradigm the following conclusions are made:

Phase-time-pace - The current structure of the system relates to Subparadigm 1. A major causal factor of the problems experienced by the system relates to the significant divergence between the distant past era (Subparadigm 1) and the present (Subparadigm 3). These two subparadigms are incongruent and cannot relate naturally. Therefore attempts are made by the system to relate them by enforcing artificial communication between the system and the global environment. This causes the communication process to be distorted, since effective relationships typically can only take place between systems from within the same subparadigm.

The financial accounting and reporting system cannot dictate the global informational and intellectual attributes of the present-time paradigm to regress to the distant past so as to accommodate its current restrictive structure. Instead, it will 
have to adjust its system, which according to the present subparadigm should be dissipative by nature.

Intellectual capacity - According to the suggested paradigm, the present global intellectual era necessitates spiritual intelligence. Due to the high professional stature of the system it can be assumed that it has the ability to attract sufficient intellectual capital. However, little attention is given to emotional or spiritual abilities. IQ is emphasised in Subparadigm 1. It matches with the phase-time-pace of the current financial accounting and reporting system, but not with intellectual demands of the present, which is spiritual intelligence. Until this disparity is successfully addressed, it will be impossible for a transformation to take place, as it predominantly needs to be initiated from "within" the system. "Pure change, real duration, is something spiritual. Intuition is what attains the spirit, duration, pure change" (Goldberg 2001:92).

System - The structure of the system relates to the mechanistic "building block" approach of the distant past (Subparadigm 1), which confirms its unrelatedness to the present. Again, it needs to be stressed that individual systems are activated to transcend by a global force of information and intelligence, which is the result of the collective actions of individual systems. Therefore, a global force cannot determine its own destiny; it cannot even accommodate an individual system that is not transcending according to global speed. Also, with a global transcendence into a new time paradigm, the amount of competition increases. The "outer" environment of a disintegrated system will quickly be consumed by more related systems. This situation is already emerging in the accounting field, as other professions arise that are competing for the clientele of the current financial accounting and reporting system (Cooper 2002).

\section{Recommendations}

The accounting profession needs to address both the system within which it functions and the products which it subsequently delivers. The challenge lies in activating the system as a whole to transcend from the distant past to the present, as isolated individual attempts will not be sufficient to enforce change.

\subsection{Transcendence from a conservative to a dynamic dissipative (self-organising) system}

The accounting profession functions as a conservative system and reports accordingly. To develop a more affluent scientific reasoning and communication process, characteristics of holistic intelligence systems need to be explored and adopted. The suggestion is not that knowledge of the modern sciences holds the answers to all of the problems experienced in artificial and social sciences or related disciplines such as accounting, but to take note of the attributes that the 
modern sciences have found to be decisive, such as self-organising systems, contingency and complexity.

In the past, science has made enormous progress by dissecting and analysing things into parts, but modern science operates from an inverse angle. Werner Heisenberg illustrated that reality cannot be studied by dissecting it into parts (Zukav 2000). The moment a part is isolated, it is no longer part of the whole, and it changes nature. Thus, the purpose of an entity is eventually determined by the whole, and not by its parts.

Reductionism provides an understanding of the deterministic sciences, but not of higher-level phenomena, such as organisations, where new unified systems are continuously emerging. Such phenomena need to be explored as a whole, a system, where parts are interrelated and are only there because of the system.

Communication is considered to be the marketplace of the accounting profession. It is also a main ingredient in the systems approach. Communication intends to enhance relationships. The stronger these relationships, the more attractive the system's attributes - (such as independence, trustworthiness and reliability) and the larger its environment and the clearer its destiny. The accounting profession, therefore, should make deliberate attempts to enhance its communication strategy. "GAAP must come to terms with this more complex world if it is to retain its relevance" (Elliott 1991:77).

The concept of dissipation relates to concepts such as awareness, contingency, non-equilibrium, risk and uncertainty - which all have a basic futuristic orientation and a focal point in change. In contrast to a conservative, classical and deterministic system, a futuristic-oriented system is dynamic, self-organised, strongly interrelated with an outward-looking focus. It is more mind than matter oriented, so as to address the non-equilibrium world in which we live.

Initially, conflicting results were experienced with regard to the observation of the process of dissipation. Physics interpreted dissipation as degradation, or negative entropy, resulting in death. In contrast, natural scientists observed biological evolution, which was characterised by increasing complexity and irreversibility - the dissipative activity of loss created new order. "Dissipation didn't lead to the death of a system. It was part of the process by which the system let go of its present form so that it could reorganize in a form better suited to the demands of its changed environment" (Wheatley 1999:21). In such a sense dissipative systems initiate positive entropy - it regenerates. It is the latter form of dissipation that is distinctive to natural adjustment and growth and from where we are directed. Non-equilibrium is an agent of order that may lead to the development of dissipative systems. "These structures are very sensitive to global features such as the size and the form of the system, the boundary conditions imposed on its surface, and so forth. All these features influence in a decisive way the type of instabilities that lead to dissipative structures" (Prigogine 1980:103). They function in an anti-mechanical, uncertain manner, in the direction of the arrow of time, thereby deeming the principle of cause and effect irrelevant.

Meditari Accountancy Research Vol. 12 No. 12004 : 77-99 
Unlike passive dissipative (conservative) systems, dynamic dissipative systems are continuously evolving into greater complexity so as to increase their sustainability according to the changes in an unpredictable environment. They operate through relationships, and the quality thereof determines their future. Since dynamic dissipative systems are detached from mechanistic thinking and negative entropy, they cannot report or be reported on by means of conservative reporting methods.

Modern adaptive systems require a focus on the stimuli that cause them to fluctuate and grow, and on the properties of the systems that assist in their sense of awareness and readiness to adjust. In short, they require a focus on the quality of their relatedness, which cannot be expressed by mere quantification, and which is the case with conservative systems.

Einstein is often quoted to have said: "No problem can be solved from the same consciousness that created it" (Wheatley 1999:7). We should learn to observe and reflect anew on relationships that are rich and complex, and we need to do so in a more decisive way. "With relationships, we give up predictability and open up to potential" (Wheatley 1999:35). "It is the relationship that evokes present reality. Which potential becomes real depends on the people, the events and the moment" (Wheatley 1999:36).

Systems in disequilibrium have the opportunity to be highly economical. They do not have to cope with constraints such as a plethora of debilitating rules and regulations. Dynamic dissipative systems are spontaneous and creative, and do not operate according to strict hierarchies. They become more fluid and organic as bureaucracy starts to fall away. Itzkowitz remarks that "[a]s long as communication is obstructed by the use of power, and as long as that power is aimed to encourage distorted versions of truth and reality, communicative action is repressed" (1996:47). The social sciences, in the field of organisational theory, for example, did let go of numerous approaches towards fundamental issues, such as the mechanical view of organisations where bureaucracy prevailed, and where workers were perceived to be replaceable cogs in a production process (Fulmer 2000). Leadership can no longer be regarded as an extended control mechanism; the focus is now rather on the unique sets of relationships that it creates and from where it functions.

Modern science teaches that order emerges spontaneously from within open, dissipative systems. It can never be enforced, from whichever direction, for such a rigid property belongs to concept of control. According to Vladimir Nabokov, "[w]hat can be controlled is never real; what is real can never be controlled" (Prigogine 1997:154). Accountancy should thus not attempt to control either its "inner" or "outer" environment.

Contingency implies uncertainty and risk, as it allows for the exploration of various possibilities. It calls for the adjustment of social theories that aspire to predetermine outcome. 
Knowledge will always be limited to the human mind, hence financial accounting and reporting systems will never be able to reflect total truth and reality, and it should not create the impression that it could. As a closed system, financial accounting and reporting attempts to "prove" the truth by means of identifying, defining, measuring and verifying according to common agreement and not because of a correlation with reality.

A balance must be struck between portraying and predicting nothing on the one hand and everything on the other. Such an approach could provide a philosophical framework for understanding and reflecting social phenomena that form an integral part of a holistic intelligence financial accounting and reporting system.

\subsection{An increased focus on the human element in system design}

The focal point of the current accounting system is its structure and not its dynamics. Structure restricts, while dynamics causes stable change. A selforganising system gains stability from a sound awareness of what it is, where it comes from and how it relates.

An important point to take note of is the high degree of congruence between different scientific disciplines as far as the attributes of efficient systems are concerned. From a natural scientific point of view, scientists have identified attributes peculiar to those of a dynamic dissipative system, such as openness, receptiveness, relatedness, spontaneity, growth and adjustability (Fulmer 2000; Nicolis and Prigogine 1989; Waldrop 1992). From a psychological point of view, the very same attributes were independently identified as the characteristics of spiritual intelligence (Zohar and Marshall 2001).

Recent research studies (BSM Consulting 1998:1; Gouws and Van Eeden 1996:17; Parker 2000:2) indicate that the typical accountant prefers to focus on aspects such as concrete facts and detail, logical analysis, rational calculation, orderliness, clarity and low levels of ambiguity. He/She displays a slightly greater tendency towards introversion than the average population, and is prone to be calm, controlled and thoughtful. According to Zohar and Marshall (2001), the accountant belongs predominantly to the conventional personality and ego type and is mainly driven by gregariousness. He/She is conscientious, careful, conforming, methodical, obedient, orderly, persistent, practical, thrifty, but also defensive, inflexible, prudish, reactive, uncreative and exactly the opposite of the artistic type. They prefer steadiness, compliance, structure, balance, normality and predictability.

A system's ability to change can be seen in the quality of its relationships, which is dependent on the spiritual intelligence of the partakers. It is not to be found in the "objective" structure of the system itself, but in invisible mental energy forces such as open-mindedness and a willingness to explore and adjust. Should these partakers be confined to rigid Newtonian thought, so will the systems be which they design.

Meditari Accountancy Research Vol. 12 No. 12004 : 77-99 
The accounting profession is not ignorant about the challenges it will be facing in the new millennium. This topic is addressed frequently and a number of applicable quotations are hereby presented. During 1997, the American Institute of Certified Public Accountants (AICPA), issued the CPA Vision Project-2011 and Beyond. "Many of the recommendations in The Vision require important changes in the nature of being an accountant; for example, greater emphasis on professional demeanor, leadership, and interpersonal communications" (Wheeler 2001:125). Cooper suggests that "[a]ccountants need to capitalise on traditional strengths such as independence and concern for the public interest, through migrating to higher value-added activities, developing broader skills and being committed to lifelong learning" (2002:1). Wheeler also remarks that "[t]he stereotypic accountant will play a decreasing role in this new environment, yet two decades of research indicate little change in the personality makeup of those choosing to study or practice" (2001:125). John Brockwell, previously a president of the ACCA, states that "the professionals who will add greatest value are those whose minds are open, who can interpret, understand and communicate the meaning of numbers, who thrive on challenges, who relish the opportunities for lifelong learning and who embrace change" (Cooper 2002:3). In conclusion, Parker can be quoted as saying that "[t]hose accountants who are content to remain as technicist, financial compliance bean counters are destined for subordinate corporate career prospects, declining client bases and ultimately early retirement" (2000:2).

Transcendence from the distant past to the present time paradigm requires freedom and creativity. The financial accounting and reporting system should realise that a challenge to transform a system is also a challenge presented to those taking part in it. Their utilised abilities and attitudes will determine the relevance of the system to which they belong, and every attempt should be made to enhance this potential capacity.

\subsection{Establishment of a unique accounting time paradigm}

To report on the reality of complex, dissipative and self-organising systems from within the current time paradigm, in other words the present, relies on a broader perspective concerning what an accounting and reporting system should produce. It requires an all-inclusive time stance, which acknowledges and portrays relevant issues related to the past, present and future. Such an expansion of the accounting system is only possible if we revise our concept of time.

As mentioned, the financial accounting and reporting system focuses on the effects of past events, creating a perception of reality by a set process of observation and reporting standards, which direct what we choose to notice and the manner in which we reflect. Such a viewpoint originates from classical, conservative systems that played a key role in the development of abstract thinking and marked the beginning of science and modern civilisation. At the advent of classical mechanics, the concept of conservation was expanded in great detail. It was purported to be a "concept of a set of laws that provided a quantitative explanation of observation ..." (Nicolis and Prigogine 1989:46). 
However, in the present time paradigm the portraying of reality by means of predetermined, conservative issues reveals nothing more than fragments of "discovered and certain" matter; of actual dynamics and identities according to the peculiar interpretation of the constricted accounting lens.

Reporting according to the needs of the current time phase pace, means searching and reporting on the so-called hidden and unseen factors too, which eventually could be revealed as the main survival drivers of an organisation in an uncertain environment.

Reflecting on reality from both a mind and matter-oriented perspective implies the addressing of past certainties and future uncertainties, which results in the assessment of the risk of the present. Reflecting on reality also implies the incorporation of a feedback system, so as to sustain relationships. Research into these areas hold vast possibilities of enhancing the sustainability of the accounting profession and will assist the system in becoming more related to the present time paradigm.

The topic of sustaining relevance justifies further research. This article has aspired to set the stage against which such research may be conducted and from where a subsequent series of articles can be written to address the ideal accounting time paradigm and the related focal points against which an organisation may be reflected.

\section{Bibliography}

Anonymous. 2000. The Qualitative Objectives of Financial Reporting, http://redbrick.dcu.ie (11 Dec 2002, pp.1-9).

Baxter, W.T. 1988. Accounting Research-Academic Trends vs Practical Needs, The Institute of Chartered Accountants of Scotland, Edinburgh.

BSM Consulting. 1998. Careers for ISTJ Personality Types, http://www.personalitypage.com (11 Dec 2002, pp.1-2).

Capra, F. 1997. The Web of Life, Flamingo, Great Britain.

Cohen, J. and Stewart, I. 2000. The Collapse of Chaos, Penguin Books, London.

Cooper, B. 2002. The Accountant of the Future, http://www.accademy.com (11 Dec 2002, pp.1-3).

Dwyer, P. 2000. I Want It Crystal-Clear Who's to Blame, http://www.businessweek.co.za (11 Dec 2002, pp.1-3).

Edwards, J.R. 1989. A History of Financial Accounting, Routledge, London.

Elliott, R.K. 1991. Accounting Education and Research at the Crossroad, Issues in Accounting Education, Spring, pp.1-8.

Evans, T.G. 2003. Accounting Theory: Contemporary Accounting Issues, Thomson, South Western, USA. 
Flegm, G. 2000. Reconsidering current-value accounting, Accounting Today, May 2000, p.6.

Francis, J. and Schipper, K.1999. Have Financial Statements Lost Their Relevance?, Journal of Accounting Research, Autumn,Vol. 37, No. 2, pp.319-351.

Fulmer, W.E. 2000. Shaping the Adaptive Organization: Landscapes, Learning, and Leadership in Volatile Time, AMACOM, New York.

Garbutt, D. 1981. The Origins of Accounting and Writing, The Accounting Historian's Notebook, Fall, pp.10-11.

Glover, C. 2001. Emotional intelligence - what is it?, http://www.accountancyage.com (3 Jan 2003, pp.1-2).

Goldberg, L. Edited by S.A. Leech. 2001. A Journey into Accounting Thought, Routledge, London.

Gouws, D.G. 1979. Perspectives Surrounding Accounting Communication, Meditari, pp.61-82.

Gouws, J.J. and Van Eeden, R. 1996. The Structured-Objective Rorschach Test (SORT) Occupational Profile for State Accountants, Journal of Industrial Psychology, Vol. 22, No. 2, pp.15-19.

Green, W.L. 1930. History and Survey of Accountancy, Standard Text Press, USA. Horwich, P. 1992. Assymetries in Time, MIT Press, London.

Itzkowitz, G. 1996. Contingency Theory: Rethinking the Boundaries of Social Thought, University Press of America Inc, USA.

Kahn, J. 2002. Off balance sheet-and out of control, http://proquest.umi.com (13 Mar 2002, pp.1-2).

Kapur, J.N. and Kesavan, H.K. 1992. Entropy Optimization Principles with Applications, Academic Press Inc, London.

Koornhof, C. A 2001. Systems Approach to Research Inquiry in Accounting: A Research Note, SAJEMS, Vol. 4, pp.254-262.

Lee, T.A. 1989. Education, Practice and Research in Accounting: gaps, closed loops, bridges and magic accounting, Accounting and Business Records, Summer, pp.237-253.

Lee, T.A. 1990. A Systematic View of the History of the World of Accounting, Accounting, Business and Financial History, Vol. 1, No. 1, pp.73-107.

Lev, B. and Zarowin, P.1999. The Boundaries of Financial Reporting and How to Extend Them, Journal of Accounting Research, Autumn, Vol. 37, No. 2, pp.353385 .

Lymer, A. 1998. The use of the Internet for Corporate Reporting - a discussion of the issues and survey of current usage in the UK, http:/www.scu.ac.uk/ schools/fsl/fisjnl/vol1996/pprs1997/lymer97.html (11 Dec 2002, pp.1-14).

Mattesich, R. 2000. The beginnings of Accounting and Accounting Thought, Garland Publishing Inc, New York. 
Nicolescu, B. 1999. The Transdisciplinary Evolution of the University Condition for Sustainable Development, http://perso.club-internet,fr/nicol/ciret/bulletin (18 May 1999, pp.1-8).

Nicolis, G. and Prigogine, I. 1989. Exploring Complexity, W.H. Freeman and Company, New York.

Parker, L. 2000. Goodbye, Number Cruncher!, http://www.cpaaustralia.com (11 Dec 2002, pp.1-4).

Parker, L. Ferris, K. and Otley, D. 1989. Accounting for the Human Factor, Prentice Hall of Australia, Sydney.

Prigogine, I. 1997. The End Of Certainty: Time, Chaos, and the New Laws of Nature, The Free Press, New York.

Prigogine, I. 1980. From being to becoming: time and complexity in the physical sciences, W.H. Freeman and Company, San Francisco.

Stent, G.S. 2001. Meaning in Art and Science. In The Origins of Creativity, Edited by Pfenninger, K.H. and Shubik, V.R., Oxford Press, New York.

Sterling, R.R. 1972. Research Methodology in Accounting, Scholars Book Company, Kansas.

Sterling, R.R. 1997. The Quest for a Science of Accounting: An anthology of the Research of Robert R Sterling, Edited by T.A. Lee and P.W. Wolnizer, Garland Publishing Inc, New York.

Waldrop, M.M. 1992. Complexity: The Emerging Science at the Edge of Order and Chaos, Simon \& Schuster, New York.

Wells, M.C. 1987. What is wrong with accounting education?, Working paper 22, Accounting Research Centre, University of Sydney.

Wheatley, M.J. 1999. Leadership and the new science: discovering order in a chaotic world, Berrett-Koehler, San Francisco.

Wheeler, P. 2001. The Myers-Briggs Type Indicator and Applications to Accounting Education and Research, Issues in Accounting Education, Feb 2001, Vol. 16, No. 1, pp.125-150.

Wolk, H.I., Tearney, M.G. and Dodd, J.L. 2001. Accounting Theory: A Conceptual and Institutional Approach, 5th edition, South-Western College Publishing, USA.

Wolpert, L. 1993. The Unnatural Nature of Science, Faber and Faber Limited, London.

Yu, S.C. 1976. The Structure of Accounting Theory, University Press of Florida, USA.

Zohar, D. and Marshall, I. 2001. SQ: Spiritual Intelligence the Ultimate Intelligence, Bloomsbury Publishing Plc, London.

Zukav, G. 2000. The Dancing Wu Li Masters. An Overview of the New Physics, Rider \& Co, London. 